\title{
The effect of market-sensing capability on knowledge creation process and innovation Evidence from SMEs in Jordan
}

\author{
Abdallah Mohammad Alshanty ${ }^{a^{*}}$, Okechukwu Lawrence Emeagwalia, Blend Ibrahim ${ }^{\mathrm{a}}$ and \\ Muneer Alrwashdeh ${ }^{\mathrm{b}}$
}

${ }^{a}$ Girne American University, Business Management Department, via Mersin 10, North Cyprus, Turkey

${ }^{b}$ Girne American University, Marketing Management Department, via Mersin 10, North Cyprus, Turkey

\section{H R O N I C L E}

Article history:

Received: December 11, 2018

Received in revised format: Janu-

ary 8, 2019

Accepted: January 30, 2019

Available online:

January 30, 2019

Keywords:

Market-sensing

Innovations

Knowledge management

\section{A B S T R A C T}

\begin{abstract}
This article aims to investigate the effect of market-sensing capability among knowledge creation and process and product innovation in small and medium-sized enterprises (SMEs) in Jordan. We propose that market-sensing capability will influence knowledge creation and process as well as product innovation. The study develops a model that contributes to the flourishing marketing management literature, i.e. the higher the knowledge creation, the higher the performance of SMEs. Data are collated from valid $(n=304)$ respondents of Jordanian SMEs. The study uses structural equation modeling (SEM) to explore the analysis and the results indicate a positive effect of market-sensing capability on knowledge creation, and process and product innovation. Knowledge creation process has also maintained a positive effect on process and product innovation. Knowledge creation process mediated the link between market-sensing capability and process and product innovation. The study suggests that market sensing abilities of an enterprise are important for SME's improvement which requires learning-positioning for firm effectiveness. In addition, managers need to harmonize their procedures concerning market sensing and learning. Future study can streamline the findings with a longitudinal design and insights can be acquired by exploring the impact of environmental factors surrounding strategic entrepreneurial orientation.
\end{abstract}

C 2019 by the authors; licensee Growing Science, Canada

\section{Introduction}

Small and Medium scale enterprises (SMEs) is such a diverse lot. This is because the term SME covers a broad range of businesses and organizations- from local dressmakers, restaurants, garage shops to computer software start-ups (Hallber, 2000). SMEs enjoy a variety of skills and sophistication, and they are also able to run in diverse social and market settings. They could be innovative, dynamic and very growth oriented, while on the other hand, they could be simple-traditional businesses contented with being small. Depending on the country, SMEs are defined based on different statistics; which could be the worth of the firm's asset, sales, or the total number of personnel employed by the business (Ayyagari et al., 2007; Perrewe et al., 2002), thus, the economic significance of SMEs is enormous in these countries in particular, and around the world in general. The World Bank in an obligation to boost employment, enhance economic development and mitigate poverty has recognized the role of SMEs

\footnotetext{
* Corresponding author.

E-mail address: alshanti0@gmail.com (A. M. Alshanty) 
(Ayyagari et al., 2006). The ability to sense the market and react to changes in the moves of market rivals, advancement in technology, latent and open demands of the consumers as well as leveraging on the competencies and assets of stakeholders will help smalls firms develop novel products or work new features and attributes into current ones to meet the demands of the existing and the new consumers, and to guarantee steadiness and withstanding of the blows arising from changes in technology and the value offering (Sołek-Borowska, 2017). In a number of previous studies, innovation has been reported to occur as a result of the ability to sense the market (Ardyan, 2016), anticipate business environment changes (Fang et al., 2014), and process and manage knowledge (Quintane et al., 2011).

Sołek-Borowska (2017) found out that SMEs take knowledge creation process quite seriously even though they may not take other aspects of knowledge management quite seriously. She reported that SMEs does what larger businesses are unable to do; which is to use joint-effort, face-to-face communication and cult of owners to create an environment encouraging the creation of knowledge. Furthermore, as a result of globalization, SMEs continue to face severe competition from everywhere on the planet. Since prior research has not examined the impact of the market-sensing capability on knowledge creation around the realm of product innovation on innovation, our research paper aims to comparatively analyse the impact of market-sensing capability on knowledge creation and process and product innovation of SMEs, and the mediating role of knowledge creation, in addition, investigates the mechanism and process that exists between the seemingly well-known relationship between market sensing and innovative performance, in this context we empirically test our research model on marketing managers and managers of services and manufacturing SMEs in Jordan. Theoretically and empirically this study has contributed to the existing inconsistent findings, and also offer useful managerial insights.

\section{Literature Review}

\subsection{Market Sensing Capability and Knowledge Creation}

An extant body of research has recognised different organizational capabilities as vital factor in the firm's bid to attain competitive advantage (Day, 1994). Market Sensing is a tool for developing an organization which is skilful at learning, perceiving, and responding to market dynamics. Jaworski and Kohli (1993) in relation to knowledge creation, gives a spot-on description of market sensing, and it goes thus "a broad generation of market intelligence by an organisation relating to present and future needs of customers, distribution of this knowledge across the organisation's functional unit, and the organization's responsiveness/reaction to the market". Knowledge creation among organizational units creates chances for shared learning and inter-unit collaboration that stimulates the formation of new knowledge (Tsai, 2001). Learning is the crucial mechanism by which information and practical knowledge are formed and preserved within an organisation. According to Nonaka et al. (2006), the knowledge creation is the route through which knowledge is made available, amplifying this knowledge, and developing it in regard to a firm's knowledge system. Organisational learning is captured in the knowledge system (Nonaka et al., 2006). Such sensing knowledge enables more accurate prediction of the market environment, the firm's commercial ability to affect its environs and the correctness of planned actions employed by the firm at large (Cohen \& Levinthal, 1990). The resulting obsoleteness of knowledge stems from an increase in and turbulence of environmental change (Vorhies, 1998). Departments within an organization can pick up ideas from each other and gain from new knowledge gotten from other units. As discussed earlier, knowledge-based view of the firm (KBV) theory offers the entrenching of knowledge in an organisation's market sensing capability. Thus, market sensing ability can generate high market knowledge, which is speculated to be keen for any active capability (Teece, 2007;2012). Accordingly, a firm's market sensing capabilities have a positive influence on knowledge creation of firms.

\section{$\mathbf{H}_{1}$ : Market sensing capability has a significant impact on knowledge creation of SMEs.}




\subsection{Market-sensing capability, process and product innovation}

The competence of a firm lies in its ability to recurrently carry out tasks which correlate indirectly or directly to the firm's ability to create value through the conversion of the output from inputs (Grant, 1996a). Most businesses obtain various capabilities that allow them to perform certain activities required to promote its goods or services through the value chain. Product improvement is a core competency strategy of market-driven business (Lukas \& Ferrell, 2000). The development of products that are differentiated, improved upon and general developmental abilities permits firms to outclass firms that are less market-inclined (Vorhies, 1998). Innovativeness can be seen as the acceptance or development of novel, appropriate, and unique products or services by a firm. It is also a firm openness for embracing new concepts, products, and procedures, consist of the firm's readiness to transform and adopt latest technology and market trends (Rakthin et al., 2016). Openness for varying market needs usually results in offering new products and services that suit customer changing needs and anticipation (Jaworski \& Kohli, 1993; Andreou et al., 2017). Thus, the improvement in marketing abilities will enhance organizational method of reacting to problems and opportunities created by environmental instability (Vorhies, 1998). According to Lukas and Ferrell (2000), customer and competitor inclinations have various implications on the development of a new product. The tendency to procure external market information, or an idea of customer desires, needs, and service procedures, is identified as imperative for new innovation (McKelvie et al., 2018). According to Teece (2007) posited that major reliable findings from experimental studies are the probability that innovation will be profitable in the market. The systematic nature of technological advancement aggravates the need for new product and external market search. Moreover, market sensing ability sees to it that the quality of products being produced is better, that post sales services are offered in order to keep an existing customer and support the firm to achieve more marketing and financial feat (Rakthin et al., 2016). On the bases of the above statements, it is postulated that a firm market sensing skill has a positive influence on procedures and a new offering of a firm.

\section{H2: Market sensing capability has a significant impact on process and product innovation of SMEs.}

\subsection{Knowledge creation, process, and product innovation}

Studies on knowledge creation are basically used to show the development processes and effects of several forms of knowledge in an organization (Ben-Menahem et al., 2016). Research works on knowledge creation at the internal level suggest that there are two ways of comprehending the knowledge formation process in organizations. The first is the internal view and the second is the ecosystem view (Peschl \& Fundneider, 2014). Advocators of internal view stressed that new knowledge starts with cognitive metaphors that connect conflicting models, which is formed when previous knowledge is circulated and transmitted within staffs of an organization (Nonaka \& von Krogh, 2009). The environmental difference has been known to influence the firm's strategy as well as organization structure (Miller \& Shamsie, 1996). Quintane et al. (2011) opposed that the process of knowledge formation permits the collaboration and devotion of specific knowledge from various areas of operation. Thus, redundancy can be corrected, enhances process effectiveness, and increase the level of new product expansion. However, Sankowska (2013) pointed out that organization which adapts strategic knowledge formation possess the tendency to reach novelty and process developments. Therefore, the connection that exists between knowledge formation and innovation is said that Knowledge formation has a great influence on processing and product innovation in an organization.

$\mathbf{H}_{3}$ : Knowledge creation has a significant impact on process and product innovation of SMES. 


\subsection{Mediating role of knowledge creation}

Identifying market needs enable organizations to perceive those market needs and desires, and if there are some changes in demand, the organization can react promptly to the changes and meet such needs by presenting appropriate offering or render service. That is, the ability to perceive a market will determine organization reaction to the needs and desires of the customer. In respect of the above assertion, the more innovative an organization is, the faster in adjusting its products to deliver satisfactory benefits to customers, thus, this is applicable to firm's who are innovative and productive in introducing new products and services (Quintane, 2011). Various approaches have been applied in market-sensing abilities assessment including process and product innovation (Cladea, 2014). Assenting to Day (1994), marketing methods operation is usually business precise, hence the improvement of essential marketing abilities arise as a means for individual's combination of knowledge and capacities with the available resources.

Valued competences, like marketing capabilities, cannot be imitated with ease, replaced, or conveyed within rivals; therefore, these capabilities make the base for a viable competitive edge (Grant, 1996b; Möller \& Anttila, 1987). Therefore, a firm is encouraged to form a strong competitive advantage to go beyond regular market operation by presenting a natural greater offering to the customers. Research has shown that knowledge formulation presents necessary raw material for innovation in a way to distinct information, new understandings, a different perspective, enhanced creativity, cooperation, partnerships with third parties, and constant learning (Quintane et al., 2011; Sankowska, 2013). If a firm lacks these attributes, it hampers every attempt for innovation. This is in agreement with Galunic and Rodan (1998) who suggest that context-specific knowledge is unlikely to be used-up right away. Secondly, external knowledge gleaned from market sensing is better exploited when combined with the current knowledge within the firm. Businesses can innovate better when current knowledge within the system is employed alongside well-internalized knowledge from external sources (Shu et al., 2012). Therefore, the connection between knowledge creation and innovation is hypothesised that; the process of knowledge creation mediates market-sensing ability and process and product innovation in a firm.

\section{H4: Knowledge creation maintains a significant mediating impact on the relationship between market- sensing capability and process and product innovation of SMEs.}

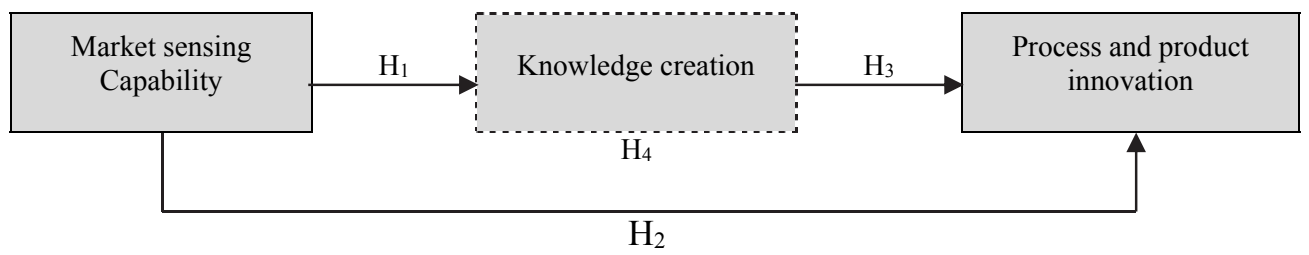

Fig. 1. Structure of the proposed model

\section{Methodology}

\subsection{Design and Sampling}

A field study has been conducted in Jordan on all managers of services and manufacturing SMEs. We have finalized the survey instrument. To avoid selection bias, we have used survey monkey sampling size calculator to determine the right number of SMEs needed for this study. Based on the outcome, 304 services and manufacturing SMEs were appropriate to conduct the study, this figure was based on Margin of Error (\%):5\% and Confidence Level (\%): 95\% with a Population Size: 1,442 registered SMEs are operating in Amman and Irbid, Jordan (http://www.jordanyp.com/category/Small_business).. Subsequently, data collected via questionnaires were distributed based on simple Random sampling (SRS) techniques and included techniques for reducing or eliminating errors in the output of survey responses. 


\subsection{Measurement}

The survey developed has two sections: Section one entails questions for the researcher variables categorized into four sub-sections, and section two entails demographic characteristics of the participating firms. Research constructs and items captured for market sensing capability and a five items scale was adopted (Cohen, \& Levinthal, 1990). Here 1 stands for (strongly disagree) and 5 (strongly agree). The knowledge creation process was captured using 10 items validated by Nonaka et al. (1994), using a 5point rating scale $(1=$ strongly disagree to $5=$ strongly agree $)$. Product and process innovation were modeled and captured with 11 items utilized by Škerlavaj et al. (2010). The items were formulated on a 5-point response scale, and scores closer to 5 indicate that the enterprise places more emphasis on product, service, technical and process innovation.

\subsection{Data collection and Analysis}

Data were collected during the month of June 2018 from marketing managers and managers of SMEs in Jordan, three hundred and fifty questionnaires were distributed to participants, three hundred and four valid responses were obtained, Out of the 304 SMEs that participated in the study, 44.4\% (135) have between 51 and 100 employees; 55.5\% (169) of the SMEs have less than 50 employees and the rest have more than 100 employees. The profile of the SMEs is respect to employee numbers indeed reflects The Jordanian Ministry of Industry and Trade SMEs classification. An over whelming number of SMEs $57.8 \%$ (176) that participated in the study operate in the service industry and $42.1 \%$ (128) operate in the manufacturing industry We assess the number of employees working in Research and Development (R\&D) departments having various educational certificates. About 49.3\% (150) of employees working in (R\&D) departments have a bachelor's degree, 35.1\% (107) have higher degrees and $15.4 \%$ (47) have diploma like associate degrees.

The educational level of the employees working in R\&D departments highlight that the sampled SMEs are indeed having high intensity for product and process development for innovation. To analyze the data first, frequency analysis with SPSS (Bacon, 1997) was carried to assess the demographic set-up of the responding SMEs, and to evaluate the representativeness of the sampled SMEs. Second, confirmatory factor analysis was conducted with AMOS to assess the theoretical structural of the factors under investigation, the factors weights such as standardized factor loadings, t-statistics, goodness fit indices, convergent and divergent validity, and reliability of the model and the factors constituting the model were evaluated depending on the method used in recent research (Elrehail, 2018; Alrwashdeh et al., 2019). Third, the linear association among the variables was assessed using Pearson correlation analysis, in doing so, we were able to anticipate the direction and nature of the relationship that exists among the variables. Fourth, after satisfying several conditions such as convergent and divergent validity, and model fit indices among others. The pay-off now is to assess the structural effects of the independent variable on the proposed mediator and the dependent variable and to assess the mediator variable mediating characteristics.

\section{Data Analysis and Results}

\subsection{Model Fit Indices Validity and Reliability of Scales: The Measurement Model}

The three constructs proposed model (See Fig. 2) produced the acceptable model fit indices given Table 1 column 2, and the benchmarks are presented in column 3. Precaution was taken as to the cross-sectional and self-report nature of the study dataset, which makes it prone to common method bias (Donaldson, \& Grant-Vallone, 2002). 
Table 1

Goodness-of-fit indices

\begin{tabular}{lll}
\hline Model & Measurement model indices & Benchmark \\
\hline Chi-square & 1434.745 & \\
Degree of freedom & 1028 & \\
Relative Chi-square & 1.563 & $<5$ \\
GFI & 0.874 & Near 1 is perfect \\
NFI & 0.924 & Near 1 is perfect \\
CFI & 0.996 & Near 1 is perfect \\
TLI & 0.993 & Near 1 is perfect \\
IFI & 0.991 & Near 1 is perfect \\
RMR & 0.034 & $<0.06$ \\
RMSEA & 0.042 & $<0.08$ \\
PCLOSE & 0.001 & $<0.05$ \\
\hline
\end{tabular}

Table 2 presents the CR values, all of which were also above the threshold. Similarly, the AVE coefficients explained by each construct were also above the threshold of .50 Cronbach alpha coefficients which also exceeded the threshold of .70 .

\section{Table 2}

Reliability and validity of the survey items

\begin{tabular}{lccc}
\hline Variable & AVE & CR & $\alpha$ \\
\hline Market-sensing capability & 0.687 & 0.909 & 0.912 \\
Knowledge creation process & 0.695 & 0.972 & 0.970 \\
Product and Process Innovation & 0.691 & 0.962 & 0.960 \\
\hline
\end{tabular}

Note: CR, construct reliability; AVE, average variance extracted; $\alpha$, Cronbach's alpha

\subsection{The linearity of The Model (Correlation)}

This study adopted Pearson correlation technique in SPSS to determine how closely the variables of interest co-vary with each other. The standardized directions include a -1 (perfect negative correlation), 0 (no correlation) to +1 (perfect positive correlation). Results of the coefficient of correlation in Table 3 shows that market-sensing capability had a positive connection with knowledge creation process $(\mathrm{r}=$ $.942 ; \rho<.000)$, and product and process innovation $(\mathrm{r}=.936 ; \rho<.000)$. Finally, knowledge creation process has a positive connection with product and process innovation $(r=.964 ; \rho<.000)$. The mean scores were relatively high with market-sensing capability $(\mathrm{M}=3.908$, S.D $=.869)$ in addition Knowledge creation process $(\mathrm{M}=3.879, \mathrm{~S} . \mathrm{D}=.859)$, at the top, follow by product and process innovation $(\mathrm{M}=3.889, \mathrm{~S} . \mathrm{D}=.857)$.

\section{Table 3}

Correlations using Pearson coefficients in SPSS

\begin{tabular}{llllll}
\hline Variables & Mean & SD & 1 & 2 & 3 \\
\hline Market-sensing capability & 3.908 & .869 & - & & \\
Knowledge creation process & 3.879 & .859 & $.942^{* *}$ & - & \\
Product and Process Innovation & 3.889 & .857 & $.936^{* *}$ & $.964 * *$ & - \\
\hline
\end{tabular}

Note: Composite scores for each variable were computed by averaging respective item scores.

\subsection{Hypotheses Testing}

Table 4 and Fig. 2 illustrate the results from SMEs; the direct path between market-sensing capability and knowledge creation process $(\beta=.942, \mathrm{p}<.001)$ is positive and significant, in support of $\mathbf{H 1}$. Correspondingly, the direct path between market-sensing capability and product and process innovation $(\beta=.132 \mathrm{p}<.001)$ is positive and significant, in support of $\mathbf{H 2}$. In regard to the relationship between the knowledge creation process and product and process innovation, estimation results show that the 
relationship is positive and significant $(\beta=.607 \mathrm{p}<.001)$, in support of $\mathbf{H 3}$. Hypothesis 4 states that knowledge creation process will mediate the relationship between market-sensing capability and product and process innovation. The authors abide by the criteria's set forth by the above-mentioned researchers to examine the presence of mediation effect in the model by employing a bias-corrected bootstrapping with a simulated sample $n=5,000$ and a $95 \%$ confidence interval. With regard to this, results show that market-sensing capability had a positive and significant indirect effect on product and process innovation through knowledge creation process $(\beta=.577 \mathrm{p}<.01)$. The bias-corrected estimate suggested a partial mediation as follows (95\% confidence interval: .462 and .699). This outcome lends support to $\mathbf{H 4}$.

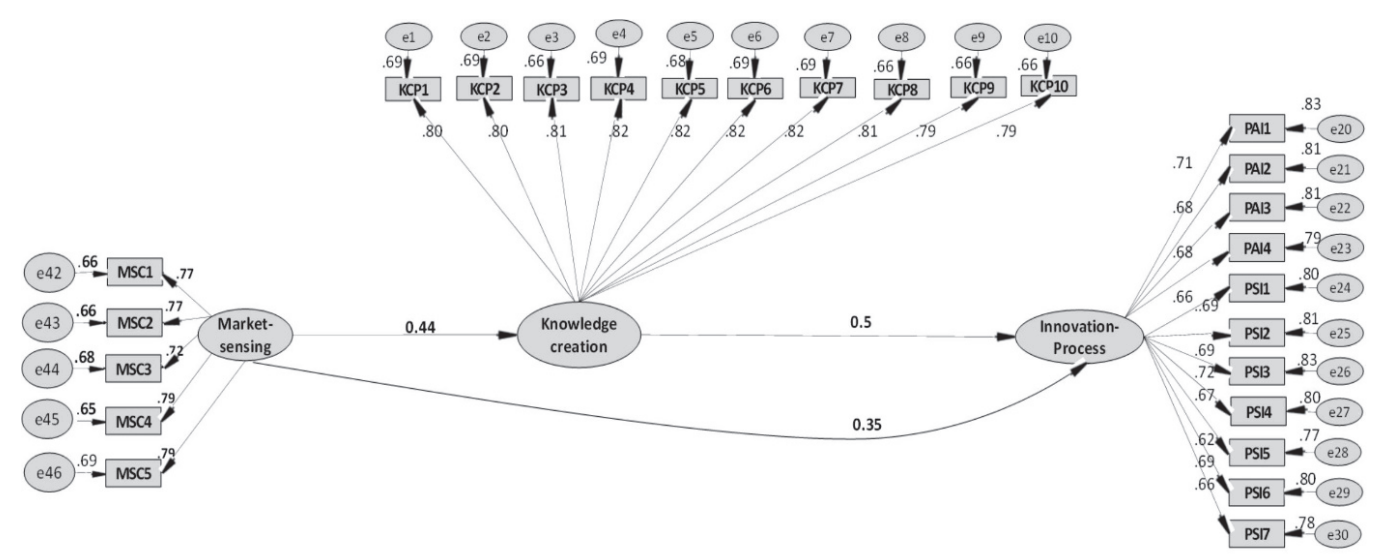

Fig. 2. Structural Equation Model, Resulted from SMEs

\section{Table 4}

Results of the implementation of SEM

\begin{tabular}{llllll}
\hline Independent variables & Independent variables & Beta $(\beta)$ & $\mathrm{t}$ & $p$ \\
\hline Market-sensing capability & Knowledge creation process & $.931(.942)$ & 0.12 & 43.980 & $* * *$ \\
Market-sensing capability & Product and Process Innovation & $.122(.132)$ & .032 & 3.297 & $* * *$ \\
Knowledge creation process & Product and Process Innovation & $.557(.607)$ & .032 & 14.522 & $* * *$ \\
\hline Note: Beta, unstandardized estimates, $\beta$, standardized estimates; S.E, standard error; t, t-value; *Significance level p $<0.05$; ***significance level p < 0.01
\end{tabular}

\section{Discussion}

This study has investigated the inter-relations among the market-sensing capabilities, knowledge creation process and product/process innovation in SMEs. The outcome from our examination shows that our research hypotheses were sustained. The results show that SMEs that possesses good market-sensing capabilities would be able to create knowledge. This is in agreement with Ardyan (2016) suggestion that when SMEs senses the market, their primary goal is not enterprise profit or growth but to possess the knowledge of what their consumers need and then use the knowledge to offer appropriate product and services based on the customer's need. The findings show that SMEs that possesses good market-sensing capabilities would be more innovative than those that do not. This outcome is similar to those obtained by previous research (Calantone et al., 2002; Keskin, 2006), where the results revealed that the higher the ability of an enterprise to sense the market, the better and the more effective it becomes at being innovative. While it has been reported that managers/owners of SMEs do not fully comprehend market sensing's primary ideas (Ardyan, 2016), empirical investigations; including this study's findings have shown that SMEs managers/owners are well able to learn about the market. This is probably because SMEs are closer to their consumers, making it easier for the SMEs to understand their consumers' explicit and salient needs; fostering the creation and delivery of services and products that are fit to meet these needs and wants. This study has also found that knowledge creation process had a substantial positive association with product/process innovation. Previous studies (Binbin et al., 2012; Popadiuk \& Choo, 2006; Ramírez et al., 2011), have identified that the knowledge creation process of a firm plays in its innovativeness. Nonaka and Takeuchi (1995) particularly highlighted the 
knowledge creation process as the facilitator for innovativeness in a firm. The contribution that makes our finding distinct is the Arabian and SMEs context, as little has been done. Moreover, the inconsistent findings are major set-back, however, researchers will have better insights with this outcome. Knowledge creation mediated the link between market-sensing capabilities and product/process innovation. Knowledge obtained from the market sensing becomes the resource that SMEs can use to ensure continuous innovation. Lindblom et al. (2008) performed an investigation on retail entrepreneurs and found that the capability to sense the market and business performance such as innovation had a rather weak relationship. They explained that this could be because other factors influencing the association between market-sensing and performance such as innovation was not considered in their model/analysis and one of such factor could be the process of knowledge creation. Thus, they corroborated the findings of this study that knowledge creation process successfully mediates the relationship between the market-sensing capabilities of SMEs and their innovativeness in process and products.

\section{Conclusion}

Drawing insight from the hypotheses, it has been recognized that market sensing is required for active learning-positioning in SMEs. Furthermore, market sensing is adopted with learning-positioning for firm effectiveness. The information obtained from consumers, rivals, and majorly from the market, affect how they explore, how they attend to, and how they relate the result for the innovative and overall function of knowledge. Additionally, research suggests that SMEs managers need to harmonize their procedure concerning market sensing and learning. The existence of an exigency fit well with these research paradigms that make firm function perfectly. Following the higher level of concern between researchers and specialists in an innovative firm, research exertions which incorporate the market recognition planned invention will be enormously valued, on other hand, the findings produce practical backing for knowledge formation concept, the tendency to reconcile the association amongst market sensing abilities and novelty; it also exerts a straight influence on a firm's innovation.

\section{Future Research}

Despite this, this study is not without limitations. The findings cannot necessarily be generalized to other countries with less or more national resources and structures. Moreover, the research design is the cross-sectional type, this also limits and interfere with causal impacts, additionally, future study can adopt multi-source data design to corroborate the present findings and abate the effect of social desirability bias or common method bias. Further insights can be acquired by exploring in depth the impact of environmental factors surrounding strategic entrepreneurial orientation. Also from statically side future studies can focus on conduct a meta-analysis study especially in the light of the fact that there are a number of quantitative studies that have accompanied over the area of knowledge creation and innovation. The future meta-analysis studies can explore the moderator effect e.g. economic development (compare developing and developed countries) based on the study of Aljarah et al. (2018). Thus, it is believed that such research endeavors would contribute to the current literature.

\section{References}

Aljarah, A., Emeagwali, L., Ibrahim, B., \& Ababneh, B. (2018). Does corporate social responsibility really increase customer relationship quality? A meta-analytic review. Social Responsibility Journal, SRJ-08-2018-0205.

Alrwashdeh, M., Emeagwali, O., \&amp; Aljuhmani, H. (2019). The effect of electronic word of mouth communication on purchase intention and brand image: An applicant smartphone brands in North Cyprus. Management Science Letters, 9(4), 505-518.

Andreou, P. C., Harris, T., \& Philip, D. (2017). Measuring Firms' Market Orientation Using Textual Analysis of 10-K Filings (December), 1-45.

Ardyan, E. (2016). Market sensing capability and SMEs performance: The mediating role of product innovativeness success. International Journal of Advanced and Applied Sciences, 2, 79-97. 
Ayyagari, M., Beck, T., \& Demirguc-Kunt, A. (2007). Small and medium enterprises across the globe. Small Business Economics, 29, 415-434.

Ayyagari, M., Demirgüç-Kunt, A., \& Maksimovic, V. (2006). How well do institutional theories explain firms' perceptions of property rights?. The review of financial studies, 21(4), 1833-1871.

Bacon, L.D. (1997). Using Amos for Structural Equation Modeling in Market Research, SPSS, Chicago.

Ben-Menahem, S. M., von Krogh, G., Erden, Z., \& Schneider, A. (2016). Coordinating knowledge creation in multidisciplinary teams: Evidence from Early-Stage Drug Discovery. Academy of Management Journal, 59(4), 1308-1338.

Binbin, Z., Jiangstao, D., Mingxing, L., \& Tongjian, Z. (2012). The empirical research on independent technology innovation. Knowledge Transformation and Entreprise Growth RISUS, 3(2), 19-26.

Calantone, R. J., Cavusgil, S. T., \& Zahao, Y. (2002). Learning orientation, firm innovation capability, and firm performance. Industrial Marketing Management, 31(6), 515-524.

Carson, D., Cromie, S., McGowan, P., \& Hill, J. (1995). Marketing and Entre-preneurship in SMEs: An Innovative Approach. London, UK: Prentice Hall.

Cladea. (2014). The Market Sensing Capability: Measure Development and Validation The Market Sensing Capability Concept: Measure Development and Validation Using Confirmatory Factor Analysis Introduction.

Cohen, W. M., \& Levinthal, D. A. (1990). Absorptive capacity: A new perspective on learning and innovation. Administrative Science Quaterly, 35(1), 128-152.

Day, G. S. (1994). The capabilities of market-driven organizations. Journal of Marketing, $58(4), 37$.

Donaldson, S. I., \& Grant-Vallone, E. J. (2002). Understanding self-report bias in organizational behavior research. Journal of Business Psychology, 17(2), 245-260.

Elrehail, H. (2018). The relationship among leadership, innovation and knowledge sharing: A guidance for analysis. Data in Brief, 19, 128-133.

Fang, S.-R., Chang, E., Ou, C.-C., \& Chou, C.-H. (2014). Internal market orientation, market capabilities and learning orientation. European Journal of Marketing, 48(1/2), 170-192.

Galunic, D. C., \& Rodan, S. (1998). Research Notes and Communications in the Firm: Resource Recombinations Knowledge Structures and the Potential for Schumpeterian. Strategic Management Journal, 19(12), 1193-1201.

Grant, R. M. (1996a). Prospering in dynamically-competitive environments: Organizational capability as knowledge integration. Organization Science, 7(4), 375-387.

Grant, R. M. (1996b). Toward a knowledge-based theory of the firm. Strategic Management Journal, 17(S2), 109-122.

Hallber, K. (2000). A Market-oriented Strategy for Small and Medium Scale Enterprises. Washington, D.C.

Jaworski, B. J., \& Kohli, A. K. (1993). Market Orientation: Antecedents and Consequences. Journal of Marketing, 57(3), 53.

Keskin, H. (2006). Market orientation, learning orientation, and innovation capabilities in SMEs: An extended model. European Journal of Innovation Management, 9(4), 396-417.

Lin, C. Y. (1998). Success factors of small and medium sized enterprises in Taiwan: an analysis of cases. Journal of Small Business Management, 36, 43-56.

Lindblom, A., Olkkonen, R., Kajalo, S., \& Mitronen, L. (2008). Market-sensing capability and business performance of retail entrepreneurs. Contemporary Management Research, 4(3), 219-236.

Lukas, B. A., \& Ferrell, O. C. (2000). The effect of market orientation on product innovation. Journal of the Academy of Marketing Science; Spring, 28(2).

McKelvie, A., Wiklund, J., \& Brattström, A. (2018). Externally acquired or internally generated? Knowledge development and perceived environmental dynamism in new venture innovation. Entrepreneurship Theory and Practice, 42(1), 24-46.

Miller, D., \& Shamsie, J. (1996). The resource-based view of the firm in two environments: The hollywood film studios from 1936 to 1965. Academy of Management Journal, 39(3), 519-543.

Möller, K., \& Anttila, M. (1987). Marketing capability-A key success factor in small business? 
Journal of Marketing Management, 3(2), 185-203.

Nonaka, I. (1994). A dynamic theory of organizational knowledge creation. Organization Science, 5(1), 14-37.

Nonaka, I., \& Takeuchi, H. (1995). The knowledge-creating company: How Japanese companies create the dynamics of innovation. Oxford university press.

Nonaka, I., \& von Krogh, G. (2009). Perspective - tacit knowledge and knowledge conversion: Controversy and advancement in organizational knowledge creation theory. Organization Science, 20(3), 635-652.

Nonaka, I., Von Krogh, G., \& Voelpel, S. (2006). Organizational knowledge creation theory: Evolutionary paths and future advances. Organization studies, 27(8), 1179-1208.

Perrewe, P. L., Hochwarter, W. A., Rossi, A. M., Wallace, A., Maignan, I., Castro, S. L., \&Van Deusen, C. A. (2002). Are work stress relationships universal? A nine-region examination of role stressors, general self-efficacy, and burnout. Journal of International Management, 8(2), 163-187.

Peschl, M. F., \& Fundneider, T. (2014). Designing and Enabling Spaces for collaborative knowledge creation and innovation: From managing to enabling innovation as socio-epistemological technology. Computers in Human Behavior, 37, 346-359.

Popadiuk, S., \& Choo, C. . (2006). Innovation and Knowledge Creation: How are These Concepts Related? International Journal of Information Management, 26(4), 302-312.

Porter, M. E. (1986). Changing patterns of international competition. The International Executive, 28(2), 13-14.

Quintane, E., Mitch Casselman, R., Sebastian Reiche, B., \& Nylund, P. A. (2011). Innovation as a knowledge-based outcome. Journal of Knowledge Management, 15(6), 928-947.

Rakthin, S., Calantone, R. J., \& Wang, J. F. (2016). Managing market intelligence: The comparative role of absorptive capacity and market orientation. Journal of Business Research, 69(12), 55695577.

Ramírez, A., Morales, V., \& Rojas, R. (2011). Knowledge Creation, Organizational Learning and their Effects on Organizational Performance. Engineering Economics, 22(3), 309-318.

Sankowska, A. (2013). Relationships between organizational trust, knowledge transfer, knowledge creation, and firm's innovativeness. The Learning Organization, 20(1), 85-100.

Shu, C., Page, A. L., Gao, S., \& Jiang, X. (2012). Managerial Ties and Firm Innovation: Is Knowledge Creation a Missing Link? Journal of Product Innovation Management, 29(1), 125-143.

Sołek-Borowska, C. (2017). Knowledge creation processes in small and medium enterprises: A Polish perspective. Online Journal of Applied Knowledge Management, 5(2), 61-75.

Škerlavaj, M., Song, J.H., Lee, Y. (2010). Organizational learning culture, innovative culture and innovations in South Korean firms. Expert Systems Applications, 37(9), 6390-6403.

Teece, D. J. (2007). Explicating dynamic capabilities: The nature and microfoundations of (sustainable) enterprise performance. Strategic Management Journal, 28(13), 1319-1350.

Teece, D. J. (2012). Dynamic capabilities: Routines versus entrepreneurial action. Journal of Management Studies, 49(8), 1395-1401.

Tsai, W. (2001). Knowledge transfer in intraorganizational networks: Effects of network position and absorptive capacity on business unit innovation and performance. Academy of Management Journal, 44(5), 996-1004.

Vorhies, D. W. (1998). An investigation of the factors leading to the development of marketing capabilities and organizational effectiveness. Journal of Strategic Marketing, 6(1), 3-23.

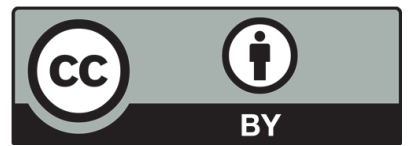

(C) 2019 by the authors; licensee Growing Science, Canada. This is an open access article distributed under the terms and conditions of the Creative Commons Attribution (CC-BY) license (http://creativecommons.org/licenses/by/4.0/). 